\title{
Carvedilol improves energy production during acute global myocardial ischaemia
}

\author{
Pedro Monteiro ${ }^{\mathrm{a}}$, Ana I. Duarte ${ }^{\mathrm{b}}$, António Moreno ${ }^{\mathrm{b}}$, \\ Lino M. Gonçalves ${ }^{\mathrm{b}, \mathrm{c}, *}$, Luís A. Providência ${ }^{\mathrm{b}, \mathrm{c}}$ \\ a Basic Research Unit in Cardiology, Cardiology Department, Coimbra University Hospital, Coimbra, Portugal \\ ${ }^{\mathrm{b}}$ Biology Department, School of Science and Technology, Coimbra University, Coimbra, Portugal \\ ${ }^{\mathrm{c}}$ Medical School, Coimbra University, Coimbra, Portugal
}

Received 29 July 2003; received in revised form 10 September 2003; accepted 16 September 2003

\begin{abstract}
Cardiac mitochondria may become dysfunctional during ischaemia, thus compromising cardiomyocyte function. Carvedilol is an $\alpha_{1} / \beta-$ adrenoceptor antagonist with antioxidant, neuroprotective, cardioprotective and vascularprotective properties, and is used to treat hypertension, myocardial ischaemia and congestive heart failure. However, its impact on mitochondrial function during acute prolonged ischaemia is unknown. We aimed to study the effect of carvedilol on cardiac mitochondrial function during acute ischaemia, using Wistar rat hearts perfused with a Langendorff system, and then submitted to ischaemia in the presence and absence of carvedilol. We determined the electrical potential of the mitochondrial membrane, $\mathrm{O}_{2}$ consumption by the respiratory chain, energy charge and the activity of the mitochondrial respiratory chain complexes. In our model, carvedilol had a preferential action on phosphorylation, increasing the mitochondrial energy charge $(0.76 \pm 0.03$ vs. $0.65 \pm 0.01$ arbitrary units; $P<0.05)$ and decreasing the phosphorylation lag phase $(28.64 \pm 4.23$ vs. $62.4 \pm 11.63 \mathrm{~s} ; P<0.05)$ during ischaemia. The larger amount of energy available allowed the preservation of the electrical potential $(201.2 \pm 2.45$ vs. $186.66 \pm 3.36 \mathrm{mV} ; P<0.05)$, thus improving mitochondrial function during acute prolonged ischaemia.
\end{abstract}

(C) 2003 Elsevier B.V. All rights reserved.

Keywords: Ischaemia; Carvedilol; Mitochondrion

\section{Introduction}

In Western countries, ischaemic heart disease is one of the leading causes of morbidity and mortality. Although this pathology has been recognised for centuries, only recently have we started to understand its cellular and molecular basis. During cardiac ischaemia, there is a relative or absolute shortage of oxygen and nutrients in cardiomyocytes, resulting in an impairment of energy production by the mitochondria. Without energy, the proper structure and function of cardiomyocytes and their components are at risk.

is This work was performed at the Basic Research Unit in Cardiology, in the Center for Neuroscience and Cell Biology of Coimbra, located in Azinhaga de Santa Comba, 3000 Coimbra, Portugal.

* Corresponding author. Cardiology Department-Coimbra University Hospital, Praceta Prof. Mota Pinto, 3000 Coimbra Codex, Portugal. Tel.: +351-239-400414/721153; fax: +351-239-780552.

E-mail address: lgoncalv@ci.uc.pt (L.M. Gonçalves).
Energy shortage and, therefore, cardiac mitochondria are at the centre of the metabolic dysfunctions induced by ischaemia. Thus, it is important to develop and use drugs able to preserve the mitochondrial energy production during ischaemia.

Carvedilol is a $\beta$ - and $\alpha_{1}$-adrenoceptor antagonist. These unique combined properties make it a vasodilator (increasing coronary blood flow) and a negative inotrope (reducing cardiac contractility) - both these actions are useful to reduce the negative impact of ischaemia on cardiac metabolism. Carvedilol is currently used to treat hypertension (Dunn et al., 1997; Feuerstein and Ruffolo, 1995; Noguchi et al., 2000), myocardial ischaemia (Ryan et al., 1999) and congestive heart failure (Cleland and McGowan, 1999; Cleland et al., 1999; Colucci et al., 1996; Dargie, 2000, 2001; Dargie et al., 1999; Feuerstein et al., 1998; Packer et al., 1996, 2001). Several authors have already shown that this drug has neuroprotective (Lysko et al., 1992a,b; Yue et al., 1994a), cardioprotective (Feuerstein et al., 1993; Yaoita et al., 2002) and vascularprotective (Yue et al., 1993, 1994b) 
properties. It is also known that carvedilol can act as an antioxidant (Yue et al., 1992). In animal models, carvedilol was able to markedly decrease the area of infarct, mainly in those models where it is known that the production of reactive oxygen species is important to induce and expand an area of acute ischaemia (Ruffolo et al., 1993).

These positive findings also occurred in human studies. CAPRICORN (Carvedilol Post infarct survival Control in left ventricular dysfunction) was a large clinical trial (1959 patients) that studied the impact of carvedilol $(6.25 \mathrm{mg}$ bid, uptitrated to $25 \mathrm{mg}$ bid) on the mortality and morbidity of patients with left ventricular dysfunction after an acute myocardial infarction; treatment was initiated before hospital discharge and less than 21 days after acute myocardial infarction (Cleland et al., 1999; Dargie, 2000; Dargie et al., 1999). In this study, patients treated with carvedilol showed a significant decrease in total mortality, cardiovascular mortality and nonfatal reinfarction (Dargie, 2001). However, the ultrastructural basis of the positive effect of carvedilol on ischaemic hearts is still to be completely determined. We hypothesised that at least part of the results shown by carvedilol in clinical trials involving patients with coronary artery disease are due to a positive impact on mitochondrial energy production during episodes of ischaemia.

Our work had, therefore, the objective of studying the influence of carvedilol on the mitochondrial function of rat hearts exposed to acute ischaemia, using an ex vivo model of perfusion with a Langendorff system. Our hypothesis was that carvedilol may prevent mitochondrial damage, thus allowing the myocyte to be supplied with mitochondrial ATP after the ischaemic period.

\section{Material and methods}

This investigation conformed with the Guide for the Care and Use of Laboratory Animals published by the US National Institutes of Health-NIH publication No. 85-23, revised 1996-(National Research Council, 1996) and it was approved by the Ethics Committee of the Centre for Neuroscience and Cell Biology of Coimbra, where the experimental work took place. All compounds were of the purest quality available and were ordered from Sigma (St. Louis, MO) or Merck (Darmstadt, Germany), except for carvedilol, which was obtained from Roche Diagnostics (Mannheim).

\subsection{Experimental groups}

Thirty Wistar rats were randomly assigned into three experimental groups: control $(n=10)$, ischaemia $(n=10)$ and ischaemia + carvedilol $40 \mu \mathrm{M}(n=10)$.

\subsection{Assembly of the ex vivo perfusion system}

Wistar rats, weighing around $300 \mathrm{~g}$, were killed by $\mathrm{CO}_{2}$ inhalation. Each heart was rapidly excised and mounted in a
Langendorff perfusion apparatus (model UP-100 from Hugo Sachs Elektronik, Germany), and then perfused at a constant flow $(25 \mathrm{ml} / \mathrm{min})$ with a Krebs modified solution $(\mathrm{NaCl} 118$ $\mathrm{mM}, \mathrm{KCl} 4.7 \mathrm{mM}, \mathrm{KH}_{2} \mathrm{PO}_{4} 1.2 \mathrm{mM}, \mathrm{NaHCO}_{3} 25 \mathrm{mM}$, $\mathrm{MgSO}_{4} 1.2 \mathrm{mM}, \mathrm{Na}_{2}$ EDTA $0.5 \mathrm{mM}$, Glucose $10 \mathrm{mM}$ and $\mathrm{CaCl}_{2} 3 \mathrm{mM}$; $\mathrm{pH}$ 7.4), gassed with carbogen $\left(95 \% \mathrm{O}_{2}-5 \%\right.$ $\mathrm{CO}_{2}$ ). Temperature was continuously monitored and maintained at $37{ }^{\circ} \mathrm{C}$ (via a thermostatic bath) throughout the perfusion period (180 min for the control group and $60 \mathrm{~min}$ for the remaining groups); $\mathrm{pH}$ was also continuously monitored with a $\mathrm{pH}$ electrode and kept stable at 7.35-7.45 during this period. Carvedilol $(40 \mu \mathrm{M})$ was added to the Krebs modified solution in the respective experimental group. Left ventricular pressure and heart rate were recorded at regular intervals.

After the initial perfusion, all the rat hearts, with the exception of the control group, were submitted to $120 \mathrm{~min}$ of ischaemia at $37{ }^{\circ} \mathrm{C}$ in a solution identical to that of the perfusion period, but without glucose and carbogen (replaced by nitrogen).

\subsection{Preparation of the biological material}

\subsubsection{Isolation of rat heart mitochondria}

At the end of the perfusion and ischaemia periods, the mitochondrial fraction from each rat heart was prepared according to the method described by Rickwood et al. (1987a). All the parameters of mitochondrial function were assessed in the isolated mitochondrial fraction.

\subsection{Laboratory methods used}

\subsubsection{Determination of protein concentration}

The protein concentration of the mitochondrial fraction was determined using the biuret colorimetric method (Gornall et al., 1949).

\subsubsection{Determination of the mitochondrial membrane potential}

Membrane electrical potential $(\Delta \Psi)$ was determined through the permanent recording of the distribution of the lipophilic cation tetraphenylphosphonium $\left(\mathrm{TPP}^{+}\right)$across the inner mitochondrial membrane. This was done with an electrode sensitive to $\mathrm{TPP}^{+}$prepared in our laboratory, according to the principles established by Kamo et al. (1979). Reactions took place at a constant temperature of $25^{\circ} \mathrm{C}$, in an open and thermostable reaction chamber, using $1 \mathrm{ml}$ of reaction solution (sucrose $130 \mathrm{mM}, \mathrm{KCl} 50 \mathrm{mM}$, $\mathrm{MgCl}_{2} 5 \mathrm{mM}, \mathrm{KH}_{2} \mathrm{PO}_{4} 5 \mathrm{mM}$ and ( $N$-[2-hydroxyethyl] piperazine- $N^{\prime}$-[2-ethanosulphonic]) acid (HEPES) $5 \mathrm{mM}$, $\mathrm{pH}$ 7.2), supplemented with $3 \mu \mathrm{M} \mathrm{TPP}{ }^{+}$and the mitochondrial suspension (volume corresponding to $2 \mathrm{mg}$ of protein, as determined by the biuret method). The determination of mitochondrial $\Delta \Psi$ was performed using the method described by Muratsugu et al. (1977) and Kamo et al. (1979). The matrix volume was assumed to be $1.1 \mu \mathrm{l} / \mathrm{mg}$ of protein. 


\subsubsection{Evaluation of mitochondrial respiratory activity}

All the assays were performed at $25{ }^{\circ} \mathrm{C}$, in a closed reaction chamber, with stable temperature and $1 \mathrm{ml}$ capacity.

Oxygen consumption was evaluated polarographically with an $\mathrm{O}_{2}$ electrode (Yellow Springs Instruments), Clark type, connected to a Kipp and Zonen recorder, through a command unit manufactured at our laboratory. Electrode calibration was done according to the protocol described by Rickwood et al. (1987b).

Reactions were initiated by adding the mitochondrial suspension to the reaction solution (as previously described). The later addition of the respiratory substrate [glutamate 10 $\mathrm{mM}+$ malate $5 \mathrm{mM}$, succinate $5 \mathrm{mM}$ or ascorbate 5 $\mathrm{mM}+N, N, N^{\prime}, N^{\prime}$-tetramethyl-P-phenylenodiamine (TMPD) $0.25 \mathrm{mM}$ ] induced an increase in $\mathrm{O}_{2}$ consumption by the mitochondrial fraction. Respiratory state 3 (characterised by a higher and faster $\mathrm{O}_{2}$ consumption) was then induced by the addition of adenosine diphosphate (ADP) $250 \mathrm{nmol}$ (62.5 nmol when using ascorbate/TMPD). After all ADP was consumed, the reaction returned to a slower velocity, respiratory state 4 . Respiratory Control Ratio was evaluated as the quotient between state 3 and state 4 .

\subsubsection{Evaluation of the energy charge}

The protocol for extraction of the adenine nucleotides (ATP, ADP and AMP) was as follows: at the end of one phosphorylation cycle induced by the addition of ADP, $250 \mu \mathrm{l}$ of the final respiratory medium was collected (corresponding to $0.5 \mathrm{mg}$ of mitochondrial protein) and added to $250 \mu \mathrm{l}$ of $\mathrm{HClO}_{4} 0.6 \mathrm{M}$ (with $25 \mathrm{mM}$ of EGTA). Five minutes later, the mixture was agitated in a vortex (to obtain a protein-free sample) and centrifuged for $2 \mathrm{~min}$ at $10,000 \times g$ in an Eppendorf centrifuge (at $0{ }^{\circ} \mathrm{C}$ ). The pellet was then removed and the supernatant was neutralised with $\mathrm{KOH} 3 \mathrm{M}+$ Tris $1.5 \mathrm{M}$ and then centrifuged at $10,000 \times g$ for another $2 \mathrm{~min}$. All procedures were conducted at low temperature $\left(0-4{ }^{\circ} \mathrm{C}\right)$. The adenine nucleotides were separated by high-pressure liquid chromatography (HPLC), reverse phase (Stocchi et al., 1985), in a Beckman Gold chromatograph, with a model 126 pump and a variable UV detector (model 166), controlled by computer. The detection wavelength was $254 \mathrm{~nm}$, using a Licrosphere 100 RP-18 column $(5 \mathrm{~mm})$ made by Merck. The protocol used consisted in isocratic elution with potassium phosphate buffer (100 mM; pH 6.5) and methanol $1 \%$. The flow rate was $1.25 \mathrm{ml} / \mathrm{min}$ for $5 \mathrm{~min}$ (to achieve nucleotide separation); the detection limit for each compound was 3-5 pmol.

The energy charge was determined according to the following formula: ([ATP $]+0.5 *[\mathrm{ADP}] /([\mathrm{ATP}]+[\mathrm{ADP}]+$ [AMP])).

\subsubsection{Determination of enzyme activity}

2.4.5.1. Complex I. The activity of this enzyme complex was evaluated by spectrofluorometry: complex I converts
$\mathrm{NADH}$ (reduced nicotinamide dinucleotide) into $\mathrm{NAD}^{+}$ (oxidised nicotinamide dinucleotide), and pyridine nucleotides produce fluorescence at $450 \mathrm{~nm}$, when excited at 366 $\mathrm{nm}$. Disrupted mitochondria (disruption induced by freezing/thawing cycles) do not possess an internal pool of reduced nucleotides (like NADH). Therefore, the heart mitochondria obtained by differential centrifugation were submitted to three cycles of freezing/thawing. Afterwards, a volume of the mitochondrial fraction corresponding to 0.4 $\mathrm{mg}$ of protein (as determined by the biuret method) was placed in quartz cuvettes containing $2 \mathrm{ml}$ of the buffer solution $\left(\mathrm{KH}_{2} \mathrm{PO}_{4} 25 \mathrm{mM}+\mathrm{MgCl}_{2} 10 \mathrm{mM}\right.$; pH 7.4) and $\mathrm{KCN} 1 \mathrm{mM}$. Fluorescence emission was determined in a Perkin Elmer spectrofluorimeter (LS 50B model) at $30{ }^{\circ} \mathrm{C}$; the reaction was initiated by the addition of NADH $50 \mu \mathrm{M}$. After the emission peak was measured, dodecylubiquinone 162.5 $\mu \mathrm{M}$ was added, with a consequent fall in fluorescence emission, graphically expressed by a line whose slope allowed the determination of mitochondrial complex I activity. In the final phase of each assay, a specific complex I inhibitor (rotenone $3.8 \mu \mathrm{M}$ ) was added, in order to guarantee that the previously obtained values were indeed complex I enzyme activity. Enzyme activity was the difference between the slopes of the lines before and after rotenone addition, determined with the FL Winlab software provided with the spectrofluorimeter. This value is expressed in arbitrary units.

2.4.5.2. Complexes $I I-I I I$. In order to evaluate the activity of complexes II-III, the method described by King (1967) was used. Enzyme activity (in nmol/min/mg of protein) was determined with the following equation: $\mathrm{AE}=[(\Delta \mathrm{Abs}) /$ $19.2] *(1000 / \mu 1$ of mitochondrial suspension $) * 1000$ in which AE represents the enzyme activity and $\Delta \mathrm{Abs}$ represents the absorbance variation per minute at $550 \mathrm{~nm}$. Results are expressed as nmol of succinate oxidized $/ \mathrm{min} /$ mg protein.

2.4.5.3. Complex IV. For the determination of complex IV enzyme activity, $\mathrm{O}_{2}$ consumption associated with cytochrome $c$ oxidation by complex IV was measured. Rotenone (specific inhibitor of complex I) and antimycin A (inhibitor of complexes II-III) were added to the reaction medium, in order to guarantee that the $\mathrm{O}_{2}$ consumption was not due to the activity of other mitochondrial enzyme complexes. This measurement was made with the technique already used for the determination of mitochondrial respiratory activity. The same reaction medium was used, to which rotenone $3 \mu \mathrm{M}$, antimycin A $0.5 \mu \mathrm{g}$, a volume of mitochondrial suspension corresponding to $0.1 \mathrm{mg}$ of protein and cytochrome $c 15 \mu \mathrm{M}$ were sequentially added.

The reaction was initiated with $10 \mu \mathrm{l}$ of Ascorbate 500 $\mathrm{mM} / \mathrm{TMPD} 25 \mathrm{mM}$, and $\mathrm{O}_{2}$ consumption was registered in the same way as for the determination of respiratory activity. $\mathrm{O}_{2}$ consumption was used to determine complex IV enzyme activity, expressed in nmol $\mathrm{O}_{2} / \mathrm{min} / \mathrm{mg}$ protein. 
2.4.5.4. ATP synthase. To determine the activity of this enzyme complex, assays were conducted at $37{ }^{\circ} \mathrm{C}$ in an open reaction chamber under permanent shaking, in a volume of $2 \mathrm{ml}$ of the reaction medium (sucrose $130 \mathrm{mM}$, $\mathrm{KCl} 60 \mathrm{mM}$, HEPES $0.5 \mathrm{mM}$ and $\mathrm{MgCl}_{2} 2.5 \mathrm{mM}$; $\mathrm{pH} 7.0$ ). After $1 \mathrm{~min}$, the time necessary to achieve the desired buffer temperature, rotenone $3 \mu \mathrm{M}$ and $0.5 \mathrm{mg}$ mitochondrial protein were added. The reaction was initiated with ATP$\mathrm{Mg}^{2+} 2 \mathrm{mM}$, and $\mathrm{pH}$ variations were evaluated continuously by a protonometric method (Madeira et al., 1974), using a Crison $\mathrm{pH}$ evaluation system consisting of a glass electrode connected to a Kipp and Zonen recorder. At the end of the reaction, $\mathrm{pH}$ titration was performed, using $10 \mathrm{mM} \mathrm{HCl}$ and $\mathrm{KOH}$. Enzyme activity was calculated using the slope of the curve for change in $\mathrm{pH}$ after the addition of $\mathrm{ATPMg}^{2+}$ and is expressed in $\mathrm{nmol} \mathrm{H} / \mathrm{min} / \mathrm{mg}$ protein. Oligomycin was not used because our preparations were essentially devoid of myofibrils or other cellular debris, as determined by electron microscopy (data not shown).

\subsection{Statistical analysis}

Results are presented as means \pm standard error (raw data or expressed as percentage of control), for the number of results indicated. Results were analyzed using the oneway ANOVA test. The level of significance used was $P<0.05$.

\section{Results}

Our results showed that oxidative phosphorylation was very sensitive to ischaemia, as demonstrated by the decrease in the respiratory control ratio, when compared with the value obtained for control group mitochondria $(2.68 \pm 0.25$ vs. $1.51 \pm 0.13 ; P<0.05)$. In the group treated with carvedilol, there was no significant improvement in respiratory control ratio $(1.61 \pm 0.08$ vs. $1.51 \pm 0.13$ - that is, $60.1 \pm 3 \%$ vs. $56.3 \pm 4.9 \%$ in the group submitted to ischaemia without carvedilol; $P=$ n.s.; Fig. 1).

When glutamate/malate was used as energy substrate, electrical potential $(\Delta \Psi)$ values decreased significantly in

\section{Respiratory Control Ratio}

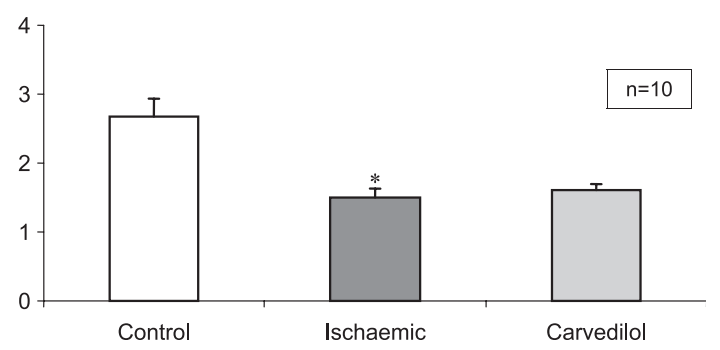

Fig. 1. Comparison of respiratory control ratio values in rat heart mitochondria (control, ischaemic and carvedilol groups) with glutamate/ malate as energy substrate. Values are presented as a ratio.
Maximum electrical potential of the inner mitochondrial membrane

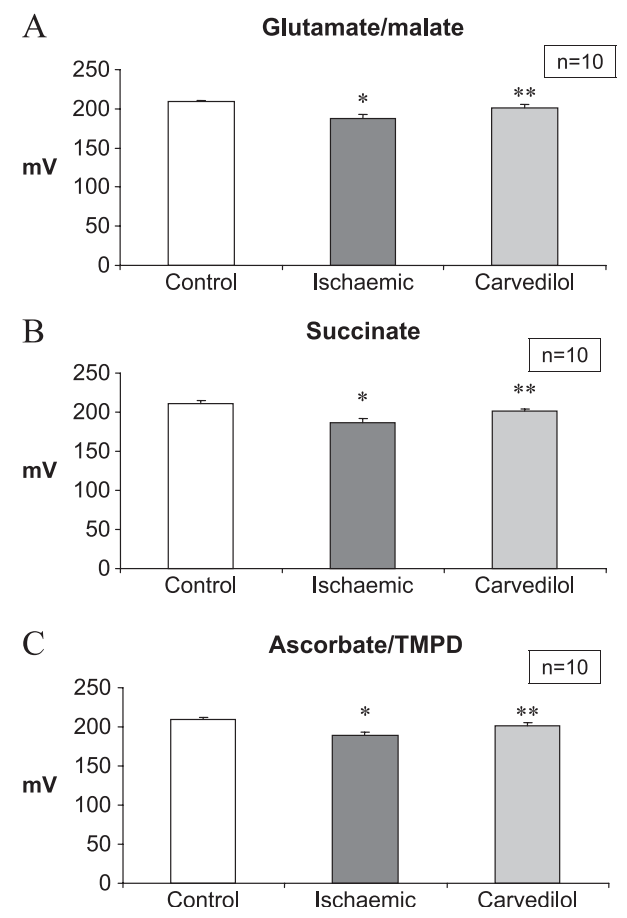

Fig. 2. Comparison between maximal electrical potential $(\Delta \Psi)$ in the control, ischaemic and carvedilol-treated hearts, after the addition of the energy substrate to the reaction medium containing rat heart mitochondria: (A) glutamate/malate; (B) succinate; (C) ascorbate/TMPD. ${ }^{*} P<0.05$ vs. the ischaemic group.

the ischaemic group, when compared to the control group $(209.13 \pm 1.37 \mathrm{mV}$ vs. $186.66 \pm 3.36 \mathrm{mV} ; P<0.001)$; a similar result was found with succinate $(211.32 \pm 3.24$ $\mathrm{mV}$ vs. $187.23 \pm 4.74 \mathrm{mV} ; P<0,05)$ and ascorbate/TMPD $(209.09 \pm 2.53 \mathrm{mV}$ vs. $189.24 \pm 3.98 \mathrm{mV} ; P<0.05)$. Mitochondria from hearts treated with carvedilol $40 \mu \mathrm{M}$ developed a significantly higher electrical potential than did mitochondria from hearts exposed to ischaemia in the absence of carvedilol. This was observed for all three energy substrates used: glutamate/malate $(95.4 \pm 1.2 \%$ in the carvedilol group vs. $89.3 \pm 1.6 \%$ in the ischaemic group$201.2 \pm 2.45 \mathrm{mV}$ vs. $186.66 \pm 3.36 \mathrm{mV} ; P<0.05$ ), succinate $(94.9 \pm 1.2 \%$ in the carvedilol group vs. $88.6 \pm 2.2 \%$ in the ischaemic group or $200.73 \pm 2.6 \mathrm{mV}$ vs. $187.23 \pm$ $4.74 \mathrm{mV} ; P<0.05)$ and ascorbate/TMPD $(96.5 \pm 1.4 \%$ in the carvedilol group vs. $90.5 \pm 1.9$ in the ischaemic group $-201.87 \pm 2.85 \mathrm{mV}$ vs. $189.24 \pm 3.98 \mathrm{mV} ; P<$ 0.05; Fig. 2A-C).

Another parameter evaluated was the amount of time needed to phosphorylate a fixed amount of ADP (250 nmol)-lag phase. The lower this value is, the quicker the phosphorylation cycle is completed. We observed a longer lag phase in the ischaemic group, when compared to control, not only with glutamate/malate $(59.08 \pm 6.82$ vs. $127.2 \pm$ $19.03 \mathrm{~s} ; P<0.05)$, but also with succinate $(66.46 \pm 6.43 \mathrm{vs}$. $275.73 \pm 45.99$ s; $P<0.05)$ and ascorbate/TMPD (31.5 \pm 
2.11 vs. $62.4 \pm 11.63 \mathrm{~s} ; P<0.05)$. The group treated with carvedilol showed, globally, a shortening of the lag phase time (vs. ischaemic group), but of different magnitude, depending on the substrate used. When glutamate/malate was used, the lag phase decrease was minimal (204.5 $\pm 12.7 \%-120.82 \pm 7.53 \mathrm{~s}-$ in the carvedilol group vs. $215.3 \pm 32.2 \%-127.2 \pm 19.03 \mathrm{~s}-$ in the ischaemic group; $P=$ n.s.). It was greater, although still non-significant, with succinate $(337.2 \pm 24.6 \%-224.54 \pm 15.99 \mathrm{~s}-$ in the carvedilol group vs. $414.9 \pm 69.2 \%-275.73 \pm 45.99 \mathrm{~s}-$ in the ischaemic group; $P=$ n.s.) and only became significant when complex IV was specifically activated with ascorbate/ TMPD $(90.9 \pm 13.4 \%-28.64 \pm 4.23 \mathrm{~s}-$ in the carvedilol group vs. $198.1 \pm 6.7 \%-62.4 \pm 11.63 \mathrm{~s}-$ in the ischaemic group; $P<0.05$; Fig. $3 \mathrm{~A}-\mathrm{C}$ ).

As already mentioned, the energy charge ([ATP $]+$ $0.5 *[\mathrm{ADP}] /([\mathrm{ATP}]+[\mathrm{ADP}]+[\mathrm{AMP}]))$ was calculated for

\section{Phosphorylative lag phase}
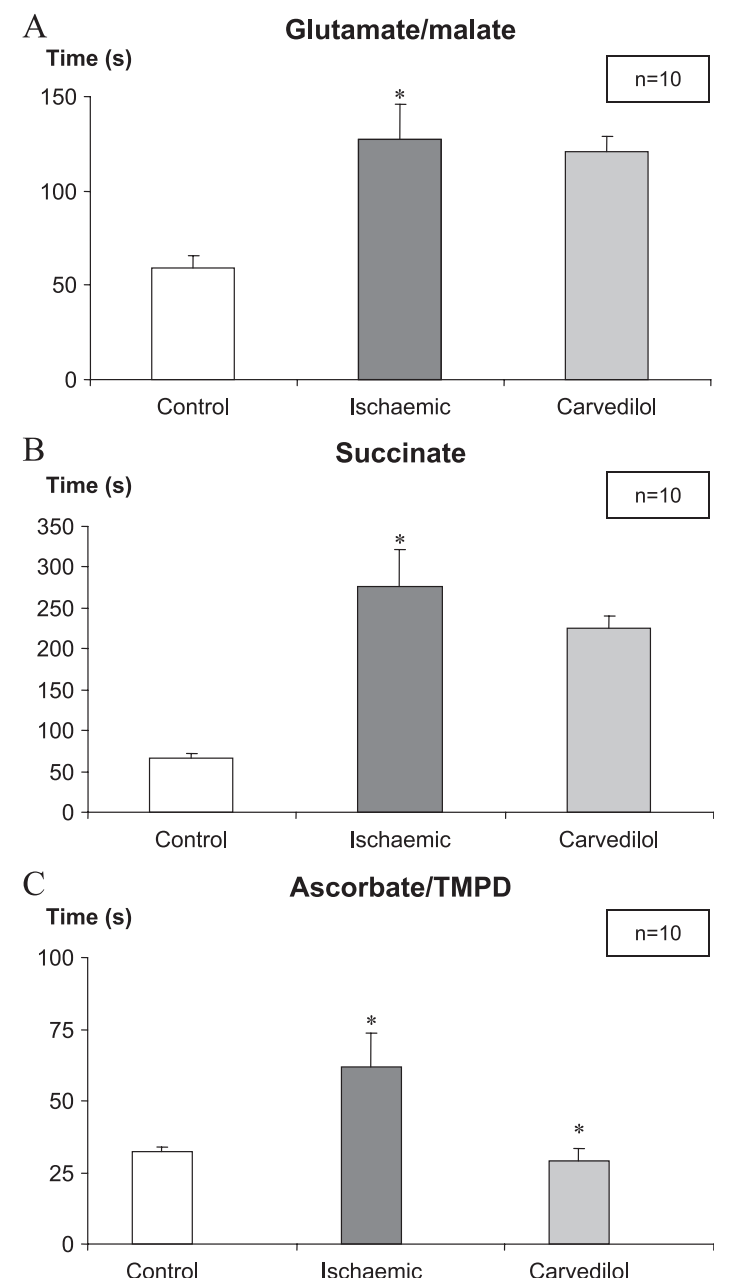

Fig. 3. Comparison of the phosphorilation lag phase in the three experimental groups (control, ischaemic and carvedilol) for each of the energy substrates studied, after the addition of $250 \mathrm{nmol}$ of ADP (62.5 when using ascorbate/TMPD) to the medium containing rat heart mitochondria and the substrate: (A) glutamate/malate; (B) succinate; (C) ascorbate/TMPD. $* P<0.05$ vs. the ischaemic group.
Energy charges

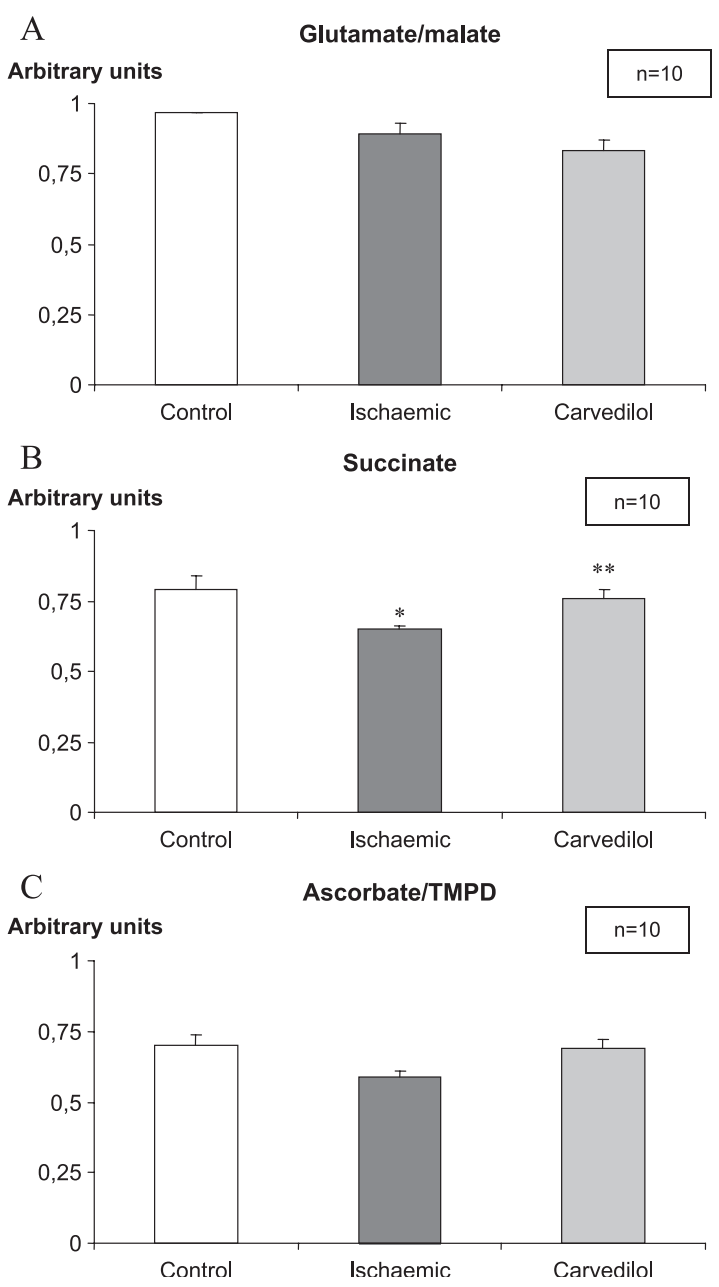

Fig. 4. Comparison of the energy charge values (obtained by HPLC) in the three experimental groups (control, ischaemic and carvedilol) for each of the energy substrates studied, after the addition of $250 \mathrm{nmol}$ of ADP (62.5 when using ascorbate/TMPD) to the medium containing rat heart mitochondria and the energy substrate: (A) glutamate/malate; (B) succinate; (C) ascorbate/TMPD. $* P<0.05$ vs. the ischaemic group.

each substrate used. The ischaemic group had a lower energy charge, when compared to the control group, regardless of the energy substrate evaluated: glutamate/ malate $(0.965 \pm 0.005$ vs. $0.89 \pm 0.04 ; P=$ n.s. $)$, succinate $(0.79 \pm 0.051$ vs. $0.65 \pm 0.01 ; P<0.05)$ or ascorbate/ TMPD $(0.7 \pm 0.04$ vs. $0.59 \pm 0.02 ; P=$ n.s. $)$; however, this difference only reached statistical significance when succinate was used as substrate. The energy charge of mitochondria from hearts treated with carvedilol was not significantly different from that of mitochondria from the ischaemic group when glutamate/malate $(86 \pm 4.1 \%-$ $0.83 \pm 0.04-$ in the carvedilol group vs. $92.2 \pm 4.1 \%-$ $0.89 \pm 0.04-$ in the ischaemic group; $P=$ n.s.) was used as substrate. However, when using succinate, the group treated with carvedilol was able to generate a significantly higher energy charge $(96.2 \pm 3.8 \%-0.76 \pm 0.03$-in the carvedilol group vs. $82.3 \pm 1.3 \%-0.65 \pm 0.01-$ in the 
ischaemic group; $P<0.05)$. The same was found when ascorbate/TMPD was used $(98.6 \pm 4.3 \%-0.69 \pm 0.03$-in the carvedilol group vs. $84.3 \pm 2.9 \%-0.59 \pm 0.02-$ in the ischaemic group; $P<0.05$; Fig. $4 \mathrm{~A}-\mathrm{C}$ ).

The activity of the respiratory chain complexes I, II-III, IV and ATP synthase was also evaluated. A statistically significant difference $(P<0.05)$ was found between ischaemic and control groups for all four enzyme complexes evaluated (complex I: 100 vs. $63.23 \pm 5.18$ arbitrary units; complexes II-III: $14,370 \pm 1174$ vs. $8592 \pm 663 \mathrm{nmol}$ succinate oxidized/min/mg protein; complex IV: $853 \pm 66$ vs. $608 \pm 58 \mathrm{nmol} \mathrm{O}_{2}$ consumed $/ \mathrm{min} / \mathrm{mg}$ protein; АTP synthase: $795 \pm 75$ vs. $426 \pm 35 \mathrm{nmol} \mathrm{H}^{+}$released $/ \mathrm{min} /$ $\mathrm{mg}$ protein). The carvedilol group showed a trend towards a higher activity for all complexes, although without reaching statistical significance. The mean values obtained were as follows: complex I $66.2 \pm 8.8$ arbitrary units in the carvedilol group vs. $63.23 \pm 5.18$ arbitrary units in the ischaemic group $(P=$ n.s. $)$; complexes II-III $66 \pm 13 \%$ $(9485 \pm 1863 \mathrm{nmol}$ succinate oxidized $/ \mathrm{min} / \mathrm{mg}$ protein) in the carvedilol group vs. $59.8 \pm 4.6 \%(8592 \pm 663 \mathrm{nmol}$ succinate oxidized $/ \mathrm{min} / \mathrm{mg}$ protein) in the ischaemic group $(P=$ n.s. $)$; complex IV $76.1 \pm 6.1 \%\left(649 \pm 52 \mathrm{nmol} \mathrm{O}_{2}\right.$ consumed $/ \mathrm{min} / \mathrm{mg}$ protein) in the carvedilol group vs. $71.3 \pm 6.8 \%\left(608 \pm 58 \mathrm{nmol} \mathrm{O}_{2}\right.$ consumed $/ \mathrm{min} / \mathrm{mg}$ protein) in the ischaemic group $(P=$ n.s. $)$; and ATP synthase $63.1 \pm 7.3 \%\left(502 \pm 58 \mathrm{nmol} \mathrm{H} \mathrm{H}^{+}\right.$released $/ \mathrm{min} / \mathrm{mg}$ protein $)$ in the carvedilol group vs. $53.6 \pm 4.4 \%(426 \pm 35 \mathrm{nmol} \mathrm{H}$ released $/ \mathrm{min} / \mathrm{mg}$ protein) in the ischaemic group $(P=$ n.s.; Fig. 5A-D).

\section{Discussion}

This work was performed to study the impact of carvedilol on the mitochondrial function of rat hearts exposed to acute ischaemia. Our working hypothesis was that carvedilol could prevent mitochondrial damage, possibly by means of its intrinsic antioxidant properties. The chosen carvedilol concentration was within the range of doses shown in the literature to have maximal antioxidant effects without being toxic to mitochondria (Abreu et al., 2000). The results showed that this drug had a different impact on the mitochondrial function parameters assessed.

Regarding the activity of the mitochondrial respiratory chain and coupling of oxidative phosphorylation, the direct effect of carvedilol was not significant. In fact, respiratory control ratio values obtained in the carvedilol group were similar to those obtained for the ischaemic group. The same was true for the enzyme activity of the respiratory chain components: values obtained for the carvedilol group were not significantly different from those for the ischaemic group. When analysing these results, it is important to remember that, when using an experimental model of acute

\section{Enzyme activities of mitochondrial respiratory chain complexes}

Complex I
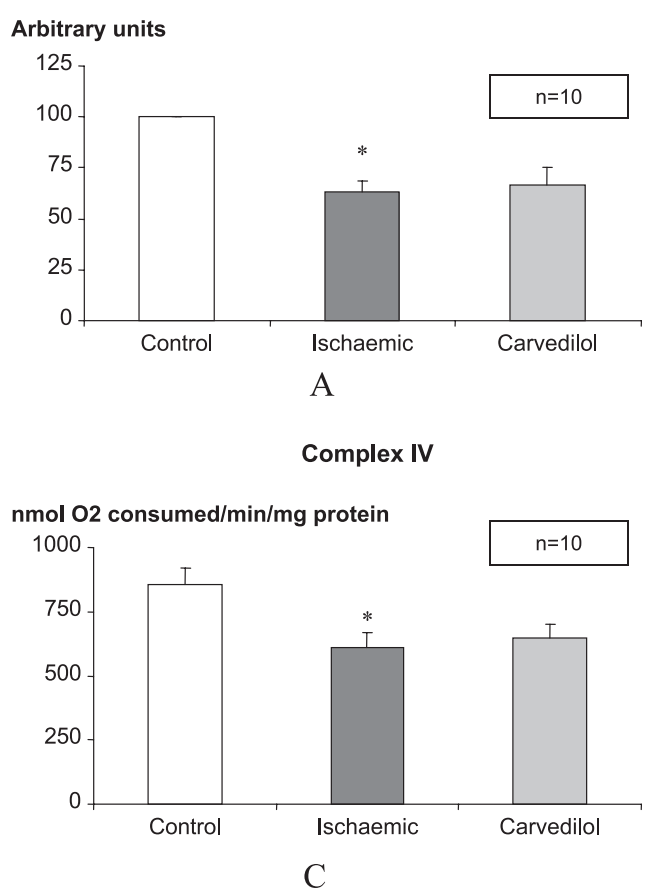

Complexes II-III
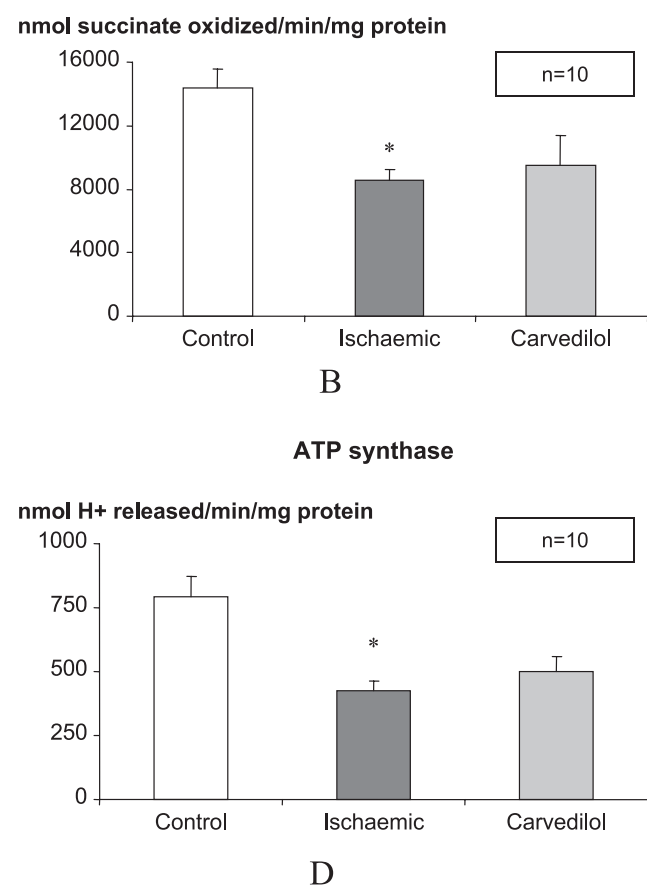

Fig. 5. Comparison of the values of the enzyme activity of rat heart mitochondria of the three experimental groups (control, ischaemic and carvedilol), for each of the complexes studied (I, II-III, IV e ATP synthase), in the presence of the substrate of each complex (NADH, succinate, ascorbate/TMPD or ATP-Mg ${ }^{2+}$, respectively): (A) complex I; (B) complexes II-III; (C) complex IV; (D) ATP synthase. $* P<0.05$ vs. the ischaemic group. 
prolonged perfusion (the control hearts were perfused during $180 \mathrm{~min}$ ), a significant deterioration of mitochondrial function is to be expected when compared with that of control hearts whose mitochondria are isolated immediately after the animal is killed (Crestanello et al., 2002a,b). Therefore, a direct comparison between the respiratory control ratio values obtained in control mitochondria and in mitochondria from hearts not submitted to perfusion (or only submitted to short-term perfusion) is not possible, as the conditions are not equivalent.

The most favourable effects of carvedilol were on the functional status of the phosphorylation system. Carvedilol was able to decrease the length of the lag phase and to increase the mitochondrial energy charge. This positive impact on cardiac mitochondrial phosphorylation during ischaemia (making it faster - shorter lag phase - and leading to higher ATP production - higher energy charge), allowed it to generate greater energy reserves, which are important to obtain a better control of the mitochondrial transmembrane electrochemical gradient, resulting in a higher electrical potential $(\Delta \Psi)$ in the carvedilol group, regardless of the substrate used.

In experimental models involving non-ischaemic hearts, carvedilol induced a slight decrease in mitochondial electrical potential, which the authors attributed to a protonophoretic effect (Abreu et al., 2000; Oliveira et al., 2000); however, it should be noted that it has not been demonstrated that such an effect also occurs during ischaemia. An alternative hypothesis is that, during ischaemia, this protonophoretic effect can be supplanted by the already demonstrated antioxidant effect of carvedilol, allowing the protection of the mitochondrial membranes from oxidation and lipoperoxidation (Oliveira et al., 2001; Rolo et al., 2001; Santos and Moreno, 2001).

However, results obtained in our experimental model can only be partially explained by the antioxidant effect of carvedilol. It is known that the production of reactive oxygen species during isolated ischaemia (not followed by reperfusion) is modest (Jassem et al., 2002), and that when oxygen is reintroduced in the system (during reperfusion), the production of reactive oxygen species increases sharply. So, in a model of ischaemia without reperfusion, a positive impact on cardiac mitochondrial function can not be attributed solely to an antioxidant action. Recent experimental work performed with animal models of coronary stenosis and coronary occlusion suggested that, in acute ischaemia settings without reperfusion, carvedilol was unable to prevent ventricular remodelling (a feature usually related to its antioxidant properties) (Yaoita et al., 2002).

When considered globally, the results obtained for the carvedilol group in this experimental protocol allow us to suggest that, during acute prolonged ischaemia (as in the ischaemic and carvedilol groups), the protective effect of carvedilol on the mitochondrial respiratory chain (via its antioxidant activity) may not be pronounced. Instead, carvedilol had a protective effect on the phosphorylation system, thus allowing a greater and faster generation of ATP as soon as oxygen became available (as in our in vitro system for measuring mitochondrial function), which is essential to the preservation of cardiac mitochondrial function (and, lato senso, to the survival of cardiomyocytes) in the context of an ischaemic insult.

Our data are concordant with the results of large clinical trials that assessed the impact of antioxidant drugs in the treatment of myocardial ischaemia. To date these clinical trials have been unable to prove a positive effect on mortality in patients with coronary artery disease (GISSIPrevenzione Investigators (Gruppo Italiano per lo Studio della Sopravvivenza nell'Infarto Miocárdico), 1999; Heart Protection Study Collaborative Group, 2002; The Heart Outcomes Prevention Evaluation Study Investigators, 2000; Stephens et al., 1996). What really distinguishes carvedilol from these drugs is its ability to generate more ATP without increasing $\mathrm{O}_{2}$ consumption. We propose that carvedilol may act during ischemia to protect the phosphorylation system, so that the system can produce large amounts of ATP quickly, as soon as the respiratory chain is again exposed to oxygen, thus solving the main problem accompanying ischaemia - the shortage of energy for myocyte recovery after reperfusion.

Our work clearly shows, for the first time, that during episodes of acute myocardial ischaemia the cardioprotective effect of carvedilol may be due to a positive impact on the mitochondrial phosphorylation system, allowing a faster and greater production of energy during the later reperfusion phase. The extra energy supply is essential to the preservation of cellular viability during the reperfusion phase that follows the ischaemic insult. This represents a clear difference from ischaemia/reperfusion settings, where carvedilol seems to act mainly as an antioxidant (Oliveira et al., 2002). This knowledge allows a better understanding of the complex mechanisms behind the positive impact of carvedilol in patients with coronary artery disease.

\section{Acknowledgements}

This study was supported by grants from the Portuguese Society of Cardiology and the Procardio.

\section{References}

Abreu, R.M., Santos, D.J., Moreno, A.J., 2000. Effects of carvedilol and its analog BM-910228 on mitochondrial function and oxidative stress. J. Pharmacol. Exp. Ther. 295, 1022-1030.

Cleland, J.G., McGowan, J., 1999. Heart failure due to ischaemic heart disease: epidemiology, pathophysiology and progression. J. Cardiovasc. Pharmacol. 33 (Suppl. 3), S17-S29.

Cleland, J.G., McGowan, J., Clark, A., Freemantle, N., 1999. The evidence for beta-blockers in heart failure. BMJ 318, 824-825.

Colucci, W.S., Packer, M., Bristow, M.B., Gilbert, E.M., Cohn, J.N., Fowler, M.B., Krueger, S.K., Hershberger, R., Uretsky, B.F., Bowers, J.A., Sackner-Bernstein, J.D., Young, S.T., Holcslaw, T.L., Lukas, 
M.A., 1996. Carvedilol inhibits clinical progression in patients with mild symptoms of heart failure. Circulation 94, 2800-2806.

Crestanello, J.A., Doliba, N.M., Babsky, A.M., Doliba, N.M., Niibori, K., Osbakken, M.D., Whitman, G.J., 2002a. Mitochondrial function during ischemic preconditioning. Surgery 131, 172-178.

Crestanello, J.A., Doliba, N.M., Babsky, A.M., Doliba, N.M., Niibori, K., Whitman, G.J., Osbakken, M.D., 2002b. Ischemic preconditioning improves mitochondrial tolerance to experimental calcium overload. J. Surg. Res. 103, 243-251.

Dargie, H.J., 2000. Design and methodology of the CAPRICORN trial-a randomized double-blind placebo-controlled study of the impact of carvedilol on morbidity and mortality in patients with left ventricular dysfunction after myocardial infarction. Eur. J. Heart Fail. 2, 325-332.

Dargie, H.J., 2001. Effect of carvedilol on outcome after myocardial infarction in patients with left-ventricular dysfunction: the CAPRICORN randomized trial. Lancet 357, 1385-1390.

Dargie, H.J., Colucci, W.S., Ford, I., Lopez-Sendon, J.-L., Remme, W.J., Sharpe, N., 1999. CAPRICORN—a study of carvedilol post myocardial infarction. Cardiovasc. Drugs Ther. 13, 24 (Abstract).

Dunn, C.J., Lea, A.P., Wagstall, A.J., 1997. Carvedilol. A reappraisal of its pharmacological properties and therapeutic use in cardiovascular disorders. Drugs 54, 161-185.

Feuerstein, G.Z., Ruffolo Jr., R.R., 1995. Carvedilol, a novel multiple action antihypertensive agent with antioxidant activity and the potential for myocardial and vascular protection. Eur. Heart J. 16 (Suppl. F), $38-42$.

Feuerstein, G.Z., Yue, T.L., Cheng, H.Y., Ruffolo Jr., R.R., 1993. Myocardial protection by the novel vasodilating beta-blocker, carvedilol. Potential relevance of anti-oxidant activity. J. Hypertens. 11 (Suppl. 1), $\mathrm{S} 41-\mathrm{S} 48$

Feuerstein, G., Yue, T.L., Ma, X., Ruffolo, R.R., 1998. Novel mechanisms in the treatment of heart failure: inhibition of oxygen radicals and apoptosis by carvedilol. Prog. Cardiovasc. Dis. 41, 17-24.

GISSI-Prevenzione Investigators (Gruppo Italiano per lo Studio della Sopravvivenza nell'Infarto Miocárdico), 1999. Dietary supplementation with n-3 polyunsaturated fatty acids and Vitamin E after myocardial infarction: results of the GISSI-Prevenzione trial. Lancet 354, 447-455.

Gornall, A.G., Bardawill, C.J., David, M.M., 1949. Determination of serum proteins by means of biuret reaction. J. Biol. Chem. 177, 751-766.

Heart Protection Study Collaborative Group, 2002. MRC/BHF Heart Protection Study of antioxidant vitamin supplementation in 20536 highrisk individuals: a randomised placebo-controlled trial. Lancet 360 , $23-33$.

Jassem, W., Fuggle, S.V., Rela, M., Koo, D.D.H., Heaton, N.D., 2002. The role of mitochondria in ischemia/reperfusion injury. Transplantation 73, $493-499$.

Kamo, N., Muratsugu, M., Hongoh, R., Kobatake, Y., 1979. Membrane potential of mitochondria measured with an electrode sensitive to tetraphenyl phosphonium and relationship between proton electrochemical potential and phosphorylation potential in steady state. J. Membr. Biol. $49,105-121$.

King, T.E., 1967. Succinate cytochrome c oxidoreductase assay. Methods Enzymol. 10, 217.

Lysko, P.G., Lysko, K.A., Webb, C.L., Feuerstein, G.Z., 1992a. Neuroprotective effects of carvedilol, a new antihypertensive, at the $\mathrm{N}$-methyl-D-aspartate receptor. Neurosci. Lett. 148, 34-38.

Lysko, P.G., Lysko, K.A., Yue, T.L., Webb, C.L., Gu, J.L., Feuerstein, G.Z., 1992b. Neuroprotective effects of carvedilol, a new antihypertensive agent, in cultured rat cerebellar neurons and in gerbil global brain ischemia. Stroke 23, 1630-1635.

Madeira, V.M.C., Antunes-Madeira, M.C., Carvalho, A.P., 1974. Activation energies of the ATPase activity of sarcoplasmic reticulum. Biochem. Biophys. Res. Commun. 58, 897-904.

Muratsugu, M., Kamo, N., Kurihara, K., Kobatabe, Y., 1977. Selective electrode for dibenzyl dimethyl ammonium cation as indicator of the membrane potential in electrical systems. Biochim. Biophys. Acta 464, $613-619$.
National Research Council, 1996. Guide for the Care and Use of Laboratory Animals. National Academy Press, Washington, DC.

Noguchi, N., Nishino, K., Niki, E., 2000. Antioxidant action of the antihypertensive drug, carvedilol, against lipid peroxidation. Biochem. Pharmacol. 59, 1069-1076.

Oliveira, P.J., Marques, M.P., Batista de Carvalho, L.A., Moreno, A.J., 2000. Effects of carvedilol on isolated heart mitochondria: evidence for a protonophoretic mechanism. Biochem. Biophys. Res. Commun. 276, 82-87.

Oliveira, P.J., Coxito, P.M., Rolo, A.P., Santos, D.L., Palmeira, C.M., Moreno, A.J., 2001. Inhibitory effect of carvedilol in the high-conductance state of the mitochondrial permeability transition pore. Eur. J. Pharmacol. 412, 231-237.

Oliveira, P.J., Rolo, A.P., Monteiro, P., Gonçalves, L., Palmeira, C.M., Moreno, A.J., 2002. Impact of carvedilol on the mitochondrial damage induced by hypoxanthine and xantine oxidase - what role in myocardial ischemia and reperfusion? Rev. Port. Cardiol. 21, 1447-1455.

Packer, M., et al., for the US Carvedilol Heart Failure Society Study Group, 1996. The effect of carvedilol on morbidity and mortality in patients with chronic heart failure. N. Engl. J. Med. 334, 1344-1349.

Packer, M.et al., for the Carvedilol Prospective Randomized Cumulative Survival Study Group, 2001. Effect of carvedilol on survival in severe chronic heart failure. N. Engl. J. Med. 344, 1651-1658.

Rickwood, D., Wilson, M.T., Darley-Usmar, V.M., 1987a. Isolation and characteristics of intact mitochondria-isolation of mitochondria from mammalian cells. In: Darley-Usmar, V.M., Rickwood, D., Wilson, M.T. (Eds.), Mitochondria: A Practical Approach. IRL Press, Oxford, pp. $4-5$.

Rickwood, D., Wilson, M.T., Darley-Usmar, V.M., 1987b. Isolation and characteristics of intact mitochondria-isolation of mitochondria from mammalian cells. In: Darley-Usmar, V.M., Rickwood, D., Wilson, M.T. (Eds.), Mitochondria: A Practical Approach. IRL Press, Oxford, pp. $11-13$.

Rolo, A.P., Oliveira, P.J., Moreno, A.J., Palmeira, C.M., 2001. Protective effect of carvedilol on chenodeoxycholate induction of the permeability transition pore. Biochem. Pharmacol. 61, 1449-1454.

Ruffolo Jr., R.R., Bril, A., Feuerstein, G.Z., 1993. Cardioprotective potential of carvedilol. Cardiology 82, 24-28.

Ryan, T.J., Antman, E.M., Brooks, N.H., Califf, R.M., Hillis, H.D., Hiratzka, L.F., Rapaport, E., Riegel, B., Russell, R.O., Smith III, E.E., Weaver, W.D., 1999. ACC/AHA guidelines of the management of patients with acute myocardial infarction: 1999 update: a report of the American College of Cardiology/American Heart Association Task Force on Practice Guidelines (Committee on Management of Acute Myocardial Infarction). Available at www.acc.org. Accessed on September 15, 2002.

Santos, D.J., Moreno, A.J., 2001. Inhibition of heart mitochondrial lipid peroxidation by non-toxic concentrations of carvedilol and its analog BM-910228. Biochem. Pharmacol. 61, 155-164.

Stephens, N.G., Parsons, A., Schofield, P.M., Kelly, F., Cheeseman, K., Mitchinson, M.J., 1996. Randomised controlled trial of vitamin E in patients with coronary disease: Cambridge Heart Antioxidant Study (CHAOS). Lancet 347, 781-786.

Stocchi, V., Cucchiarini, L., Magnani, M., Chiarantini, L., Palma, P., Crescentini, G., 1985. Simultaneous extraction and reverse-phase high-performance liquid chromatographic determination of adenine and pyridine nucleotides in human red blood cells. Anal. Biochem. $146,118-124$.

The Heart Outcomes Prevention Evaluation Study Investigators, 2000. Vitamin E supplementation and cardiovascular events in high-risk patients. N. Engl. J. Med. 342, 154-160.

Yaoita, H., Sakabe, A., Maehara, K., Maruyama, Y., 2002. Different effects of carvediolol, metoprolol, and propranolol on left ventricular remodeling after coronary stenosis or after permanent coronary occlusion in rats. Circulation 105, 975-980.

Yue, T.L., Cheng, H.Y., Lysko, P.G., McKenna, P.J., Feuerstein, R., Gu, J.L., Lysko, K.A., Davis, L.L., Feuerstein, G., 1992. Carvedilol, a new 
vasodilator and beta adrenoceptor antagonist, is an antioxidant and free radical scavenger. J. Pharmacol. Exp. Ther. 263, 92-98.

Yue, T.L., McKenna, P.J., Gu, J.L., Cheng, H.Y., Ruffolo Jr., R.R., Feuerstein, G.Z., 1993. Carvedilol, a new antihypertensive agent, prevents lipid peroxidation and oxidative injury to endothelial cells. Hypertension 22, 922-928.

Yue, T.L., Lysko, P.G., Brone, F.C., Gu, J.L., Ruffolo Jr., R.R., Feuerstein, G.Z., 1994a. Carvedilol, a new antihypertensive drug with unique anti- oxidant activity: potential role in cerebroprotection. Ann. N.Y. Acad. Sci. 738, 230-242

Yue, T.L., McKenna, P.J., Gu, J.L., Cheng, H.Y., Ruffolo Jr., R.R., Feuerstein, G.Z., 1994b. Carvedilol, a new vasodilating $\beta$-adrenoceptor blocker antyhipertensive drug, protects endothelial cells from damage initiated by xanthine-xanthine oxidase and neutrophils. Cardiovasc. Res. 28, 400-406. 